\title{
An Integrated Approach to Neuro-development, Neuroplasticity and Cognitive Improvement
}

\author{
https://doi.org/10.3991/ijes.v6i3.9034 \\ Athanasios S. Drigas $\left.{ }^{(}\right)$, Maria Karyotaki, \\ National Center for Scientific Research-Demokritos, Attica, Greece \\ dreit.demokritos.gr \\ Charalabos Skianis \\ University of the Aegean, Karlovassi, Greece
}

\begin{abstract}
Plasticity is a basic process that underlies neural and cognitive functioning, unraveling thus the former's pervasive role in development and learning. Plasticity processes operate in both normal development and in the development following early injury. However, as the neural system matures, there is a gradual commitment of neural resources to, maturationally defined functions and a concomitant loss in flexibility and in the capacity of the system to reorganize. Brain plasticity has been intertwined with induced reorganization of local patterns of connectivity in the neural system, whose specification and stabilization relies on dynamic processes that are the product of the multidirectional interaction of genetic processes, contingencies of input and the demands of the learning environment. Moreover, bioenergetic challengesexercise, diet and activity in neuronal circuits-synaptic plasticity and neurogenesis, are innately connected to cognitive function, such as learning, memory, attention, emotion regulation and human behavior.
\end{abstract}

Keywords - cognitive science, neurosciences, neuroplasticity, neurogenesis

\section{Introduction}

Neurons interconnect and communicate with each other at specialized sites, called synapses. The majority of excitatory synapses reside on dendritic spines, tiny protrusions emanating from dendrites (1). Spines contain molecular components for synaptic signaling and plasticity, such as ionotropic and metabotropic receptors, cytoskeletal and adaptor proteins as well as various signaling molecules $(2,3,4,5$, and 6). Spine formation and plasticity is fundamental both to the development and experience-dependent remodeling of neural circuits throughout human's (30) and animal's life $(7,8,9,10,11,12,13$, and 14). Furthermore, brain circuits change in response to early sensory experience, depending on the type of manipulation, the time window of manipulation and the type of neurons $(15,16$, and 17).

Rohrer first attempts to show that brain areas that researchers once assumed were only activated by spatial and bodily orientations are also activated by linguistic cues 
that describe these particular orientations, thus explaining the neural multimodal activation patterns (63). Neuronal groups are connected to a vast number of other groups regardless of spatial proximity. These many groups are reciprocally connected and functionally distinct from the rest of the brain. Due to this connectivity, small changes in environmental situations can cause new conceptual associations to be made and new behaviors to arise. Edelman suggests that reentry is the neurophysiological foundation of the "remembered present" that defines human consciousness $(64,65)$. The recursive activation of neuronal systems allows organisms that act in the moment, and in a particular problematic situation, to redeploy past patterns of behavior. Reentry functions as a construct of human conception, literally "piling together again" the various qualities and aspects of one's perceptual fields, shaping his primary consciousness. This coherence, however, does not preclude the possibility of novel forms of categorization and coordinated motor responses that arise in light of, and seek to respond to, surprising environmental conditions. Degenerate and reentrant neural circuits allow for changes in memories and concepts as new experiences occur and a new environmental context evolves. Memory, in a degenerate-reentrant system is "recategorical", re-creative, or imaginative. Hence, our bodies and their relationship with their environmental situations, continually structure human thinking (66).

\section{Diet}

Neurogenesis, the process by which neurons are born, proliferate, differentiate and integrate into established circuitry was previously thought to occur only in the embryo. It has now been demonstrated that neurogenesis occurs also in the adult brain of most animals, including humans.

Excessive intake of certain macronutrients, such as simple carbohydrates and SFA, can lead to obesity and attendant metabolic dysfunction, also reflected in alterations in structural plasticity, and, intriguingly, neurogenesis, in certain brain regions. Because of classic associations between neurogenesis and the hippocampus, in learning and cognition, this brain region has also been the focus of attention in the study of diet and neurogenesis. It has been proposed that adult hippocampal neurogenesis may link energy metabolism and cognition in order to regulate body weight functioning as an 'interface' between the two. Neuroplastic changes in the hypothalamus, including altered neurochemical phenotype, neuronal activation, synaptic connections, and dendritic growth and pruning, can be stimulated by dietary factors, not only during critical periods of development, but also in adulthood. In summary, evidence continues to build for the stimulation of adult neurogenesis, in brain regions associated with cognition, by chronic consumption of PUFA-enriched diets (18).

In a double-blind randomized interventional study, evidence showed beneficial effects of LC-n3-FA on cognition, underlining positive effects of EPA and DHA on neuronal functioning as postulated by animal experiments. More specifically, marine LC-n3-FA (long-chain omega-3 polyunsaturated fatty acids) improved executive functions, white matter microstructure, hippocampal GM volume, and vascular 
markers in healthy older adults. Regional increases in GM volume have been suggested to serve as measures of structural plasticity in the living adult human brain, for example, due to synaptogenesis, neurogenesis, and/or angiogenesis. Improvement in cognitive performance might be due to positive effects of LC-n3-FA on neuronal function, via enhancement of synaptic membrane fluidity and plasticity. Stimulation of myelin synthesis might also explain improved white matter microstructure after LC-n3-FA. In addition, DHA has been found to promote neurite outgrowth and neurogenesis in the hippocampus in addition to an increase in synaptic membrane areas and in the expression of synaptic proteins. These molecular changes might have led to the observed improvements in memory consolidation and GM volume, for example, in the hippocampus (19).

Neurotransmitters come in chemical classes, such as the amines, amino acids and peptides. The body possesses endogenous, opiate-like substances, the enkephalins, which influence pain perception and euphoria. Protein precursors of the enkephalins and related opioid peptides are the endorphins. In addition, glutamate is an excitatory neurotransmitter throughout the central nervous system, whereas glycine is a major inhibitory transmitter in the lower brain stem but not in the cerebral cortex. Synaptosomes can be maintained only in the presence of sucrose and transmitter transport requires physiologic concentrations of various ions that rupture the nerve endings (20).

Many studies have investigated into specific foods or compounds that can provide a cognitive advantage or disadvantage. Rodents on a diet that lacks essential vitamins or minerals exhibit decreased hippocampal neurogenesis, which is accompanied by impaired learning and memory. In contrast, rodents on a diet supplemented with polyphenols or omega 3 fatty acids show increased hippocampal neurogenesis as well as improved performance on cognitive tests (21).

\section{$3 \quad$ Physical Training and Experience}

Neuroplasticity refers to structural and functional changes in the brain that are brought about by training and experience throughout one's lifetime. The brain is a dynamic organ that is designed to develop in response to early experiences leading to behavioral changes as well as memory enhancement. At birth, each neuron has 7500 connections. These increase rapidly in the first 2 years of life until the synaptic connections are doubled in the adult brain. Sensory, motor and language activities in combination with environmental stimulation enhance synaptogenesis, myelination and neuronal connectivity in the first three years of one's life. With every new experience, the brain slightly rewires its physical structure and this rewiring is mediated through the signaling cascade and activation of gene transcription in the nucleus that support synaptic connections. Moreover, experience alters neural development through influencing the gene expression, the release of neurotrophins and the release of neurotransmitters like norepinephrine that play a role in normal development. These findings have radical implications for conceptualizing the dynamic interplay between nature and nurture, early in one's lifetime (22). 
Several studies have pointed at the notable increase in neurogenesis attributed mainly to physical activity associated with exercise and an enriched environment operating synergistically $(23,24)$. Running combined with sensory, social, and motor stimulation increase cerebral blood flow (25), blood-brain barrier permeability (26), and glucose metabolism (27). These changes combined might increase hormone and growth factor level, such as VEGF (28), GDNF, and BDNF (29). BDNF in particular has received considerable attention in neurogenesis regulation.

Sensory-based neuroplasticity addresses the links among sensory input, brain function, and behavior, thus on the multiple reflections of neuroplasticity or changes in the brain and their forthcoming changes in environmental input or context. Studies point to the importance of active exploration of complex environments for neuroplastic changes to occur in the brain; ongoing engagement rather than a single experience is strictly important. Moreover, doing (physical performance) has a different effect than thinking about doing. In addition, deficits in one sensory modality result in alterations in how the brain processes information in other modalities and a typical nervous system can flexibly rely on the sensory information available within the environment to complete a task. Sensory strategies used are typically, task and experience specific, and sensory processing strategies can be linked to the stage of motor performance (30).

\section{Mood, Cognition and Learning}

Newborn neurons are added to both human and rodent adult hippocampus. It is also well understood that adult neurogenesis contributes to cognition and mood alteration in addition to serving as a model system of endogenous brain regeneration $(31,32)$.

Research has shown that there is a correlation between the level of hippocampal neurogenesis and cognition and specifically, in relation to changes in hippocampusdependent learning and memory. Moreover, innate factors of the brain, such as structural plasticity, neurotrophin and hormone levels in combination with environmental factors, such as physical activity may lead to neurogenesis by hippocampus-dependent learning. However, neurogenesis can also be influenced by the activities of the immature newborn neurons as far as their survival, maturation and subsequent integration into the existing neural circuits are concerned. Furthermore, newborn neurons are behavioral regulators beyond any doubt (33).

Brain development and plasticity are complementary, but relatively independent systems. Plasticity is a basic process that underlies neural and cognitive functioning, unraveling thus the former's pervasive role in development and learning. Plasticity processes operate in both normal development and in the development following early injury. However, as the neural system matures, there is a gradual commitment of neural resources to maturationally defined functions and a concomitant loss in flexibility and in the capacity of the system to reorganize. However, brain plasticity has been intertwined with induced reorganization of local patterns of connectivity, given the available neurotrophic factors, stimulation of afferents projecting to target 
sites and stimulation emanating from the target zone (34). The effects of environmental enrichment as well as the reorganization of primary sensory systems have also been shown to affect the survival of postnatally produced neurons within the dentate gyrus of the hippocampus. Thus, specification and stabilization of neural systems relies on dynamic processes that are the product of the multidirectional interaction of genetic processes, neural systems, contingencies of input $(35,36)$ and the demands of the learning environment (37). Therefore, language, visuospatial, and affective processes are neural-specific systems, depending on plastic, but innately competitive processes occurring in the brain, due to variable input or damage to the neural substrate (38).

Learning affects not only the survival of cells but also the maturation of newborn neurons. Training with MWM tasks increases the complexity of dendritic arborization and the spine density of adult-born GCs $(39,40)$. Indeed, this learning effect appears to influence where to the neurons will eventually respond $(41,42,43)$.

Multiple studies have documented neuroplastic changes in healthy human brains as a result of normal processes, such as learning $(44,45,46)$. Studies using transcranial magnetic stimulation (TMS) to map motor cortex found significantly increased cortical representation with task practice for the involved muscle groups, suggesting increased neural connections to support task performance $(47,48)$. Similar results were found when the task was practiced mentally, suggesting that mental rehearsal alone may produce neuroplastic changes in the brain. Both cross-sectional and longitudinal studies support the induction of neuroplastic changes by musical training (49). Other forms of stimulation (e.g., TMS, deep brain stimulation) have also been utilized in treatment for various conditions by modifying activation patterns in the brain with the intention of improving functioning (50). Exercise, which has been shown to ameliorate behavioral symptoms of stress and enhance hippocampal neuroplasticity in animal models, has also been considered as a potential adjunctive treatment for neuropsychiatric conditions. Physical activity attenuates many of the harmful effects of stress $(51,52)$.

\section{$5 \quad$ Neuronal Mitochondria}

Exercise and energy restriction activate signaling pathways in neurons that bolster mitochondrial function and cellular stress resistance. Moreover, by brain autonomous and non-autonomous mechanisms described below, mitochondrial responses to bioenergetic challenges can enhance synaptic plasticity, learning and memory as well as neurogenesis. In neurons, mitochondria are critical for maintenance of membrane ion $\left(\mathrm{Na}^{+}\right.$and $\left.\mathrm{Ca}^{2+}\right)$ gradients and for neurotransmission and synaptic plasticity (53). Therefore, mitochondrial bioenergetics is pivotal for the many different ATPdependent processes that enable neurons to function and respond adaptively to environmental challenges $(54,55-59)$. Three bioenergetic challenges that stimulate adaptive responses of mitochondria in neurons are exercise, dietary energy restriction/fasting and activity in neuronal circuits. More specifically, the enhancement of brain cell-intrinsic neurotransmitters (particularly glutamate) and 
neurotrophic factors (BDNF, FGF2) as well as the enhancement of signaling molecules emanating from peripheral organs (particularly liver and muscle) including the ketone 3OHB, irisin [60] and cathepsin B [61] mediate the mitochondria-centered adaptive responses leading to the improvement of brain function and resilience (62).

\section{$6 \quad$ Mental Imagery and Self-Images}

The brain cannot tell the difference between an actual physical event and the vivid imagery of the same event (67). Therefore, preparation, repetition, elaboration, intensification and modification of behaviors can be applied through guided imagery in an attempt to improve one's confidence, controlling anxiety and final performance in educational, psychotherapeutic and athletic contexts (68). These findings strengthen evidence that imagery and perception share common processing mechanisms, and demonstrate that the specific brain regions activated during mental imagery depend on the content of the visual image (69). In addition, sensory-motor knowledge may allow the observer to generate predictions about subsequent actions that could influence sensory systems in a top-down fashion and facilitate subsequent perceptual recognition. The view promoted by Mahon and Caramazza admits that motor knowledge can influence or augment action "understanding" to some degree, but without committing to the empirically untenable position that action understanding is dependent on the motor system. This is a desirable result and deserves empirical evaluation (70).

\section{$7 \quad$ Meditation and lower frequency oscillations}

Rhythmic stimulation of frontal cortical (frontal theta) activity in an animal model can produce some of the affective changes found in humans. Artificially inducing rhythmic activity reduced stress hormones and anxiety. However, the exact brain mechanisms that support these behavioral changes in mice are elusive. Furthermore, experimental manipulation of frontal theta activity in humans would shed light on the relation between altered white matter and meditation (71-74).

Brain functions embedded in the prefrontal cortex (PFC), anterior cingulate cortex (ACC), amygdala, nucleus accumbens (NA), and default mode network (DMN) regions, such as emotional, self-referential, and reward-motivation processing, have been modulated by, a gratitude and a resentment intervention. The modulation of intra-DMN functional connectivity (FC) during the gratitude intervention might contribute to reorganization of inter-network connectivity, such as resting-state functional connectivity (rsFC) between the DMN and the executive control network (75). Given that, individuals with low anxiety have shown significant negative amygdala-dorsomedial PFC rsFC and that the strength of amygdala-PFC rsFC has been found to be a neural predictor of individual anxiety (76), gratitude intervention could play a pivotal role in reducing anxiety. Moreover, slight modulation of connections in the NA-based functional network during the two interventions might have contributed to the considerable difference in $\mathrm{rsFC}$ after the interventions through 
reorganization of the functional networks from the intervention-state to the restingstate (77).

In addition, mindfulness training was found to increase functional connectivity among dorsolateral prefrontal cortex (dlPFC) - a hub of the executive control network - and frontoparietal regions (dorsal network e.g. superior parietal lobule, supplementary eye field, MFG and ventral network e.g. right IFG, middle temporal/angular gyrus) that coordinate executive function (88).

Focused - attention meditation (FAM)'s reported major long-term benefit is cognitive - attentional control. On the other hand, loving-kindness meditation (LKM) emphasizes a state of universal love and compassion, equalizing the self and others (78, 79). Evidence supports the existence of a dissociable pattern of activation associated with FAM and LKM as evoked by cognitive (CPT) and emotion (EPT) tasks, thus depicting domain-specific plastic changes in neural activity [80]. However, long-term LKM may not be associated with change in attention-related regions, rather than with these emotion-processing regions, which may have an impact on emotion regulation and the subsequent production of positive emotions (81).

Findings of lower intra-individual variability in gain and spatial error during the antisaccade (AS) tasks indicate superior executive control and frontal lobe functioning developed through training in cultivated mindfulness (82). Mindfulness improves emotion regulation by exerting a positive influence on executive control processes (83). Furthermore, mindfulness training or practice is known to exert attenuating effects on the Default Mode Network $(84,85)$, associated with mind-wandering or stimulus-independent thought (86), which may have further enhanced the performance on the tasks.

Changes in the observed amplitude of brain electrical oscillations appear to vary across meditative techniques, although one common feature appears to be the enhanced gamma power in the parieto-occipital area. In addition, one specific finding that seems to be unique amongst these three groups of meditative practice is the enhanced alpha power seen as a trait effect in Vipassana practitioners compared to Ishashoonya yoga and Himalayan yoga tradition practitioners (87).

The Liverpool Mindfulness Model captures the core components in mindfulness meditation practice, wherein the development of more efficient attentional control is a central issue. Regular engagement in mindfulness practice develops and refines the mental core processes, primarily based on the refinement of attentional functions that interact with and facilitate regulatory processes of emotions and cognitions. Improvements in these core processes result in a more balanced mental stance or attitude that will result in physical and mental well-being, and quality of behavior. It seems that mindfully focusing on the somatosensory experiences of breathing leads to specific improvement to resource allocation and more specifically to those perceptual discrimination processes that require a higher degree of attentional control (increase of activity in medial and lateral occipitotemporal areas of the left hemisphere, whereas the activity in lateral occipitotemporal and inferior temporal regions of the right hemisphere was decreased) $(89,90)$.

Meditators selectively attend to happy faces, whereas control subjects show attentional biases towards both angry and happy faces. Long-term meditation practice 
adaptively affects attentional biases towards motivationally significant stimuli and these biases reflect positive mood and predominance of appetitive motivation (91).

Meditation training can enhance attention and improve emotion regulation through increase in alpha, beta, and gamma power bands as well as in alpha and beta coherence. Meditation gives direct access to hidden power and forces the mind to act differently to gain strength, reducing pain and stress. Increase in theta and alpha band power and decrease in overall frequency results in reduction of stress and mind relaxation with meditation (92).

\section{Brain Computer Interfacing}

Abdulkader et al. review on Brain Computer Interface (BCI) technology for communication and mind-controlling of machines, assistive robots, physiological measuring tools, various consciousness level determination systems, brain behavior measuring tools, neuroprosthetic devices, retraining healthy brain areas, human brain activity modulation as well as self-regulation learning. The various devices used for capturing brain signals can be used, non-invasively, both for training and assessment of cognitive and mental health (93).

\section{Conclusion}

Multiple studies have documented neuroplastic changes in healthy human brains as a result of normal processes, such as learning. More specifically, innate factors of the brain, such as structural plasticity, neurotrophin and hormone levels in combination with environmental factors, such as physical activity may lead to neurogenesis by hippocampus-dependent learning. Similar results were found when the task was practiced mentally (Mental Imagery), suggesting that mental rehearsal alone may produce neuroplastic changes in the brain. Both cross-sectional and longitudinal studies support the induction of neuroplastic changes by musical training. Other forms of stimulation (e.g., Brain Computer Interfacing, Mindfulness and Meditation) have also been utilized in training or treatment for various conditions by modifying activation patterns in the brain with the intention of improving functioning.

Accumulating evidence over the last years has clearly demonstrated a role for adult hippocampal neurogenesis (AHN) in hippocampus-dependent cognition and emotional control. Newborn dentate GCs (granule cells) neurons may be more "specialized" in the processing of incoming environmental information than mature GCs. A feedback loop between the cells that may be most active in encoding new information (adult-generated GCs) and the CA3 (pyramidal neurons) auto-associative network may enhance efficiency and accuracy of memory storage (94). However, several changes occurring in the dentate gyrus (DG) need to be specified in relevance to the addition of pattern-associated cohort of newborn neurons. How does top-down or cortical input regulate adult hippocampal neurogenesis (AHN) and its function in learning new information? How do adult-born hippocampal neurons regulate the HPA 
axis, which contributes to the neurogenesis-associated regulation of anxiety-related behaviors? (95)

Moreover, gratitude, focused - attention and mindfulness training have been found to modulate the intra-DMN (Default Mode Network) functional connectivity as well as increase alpha, beta, and gamma power bands of frontal lobe functioning with the aim to enhance attention and improve emotion regulation.

\section{References}

[1] Gray, E. G. (1959): "Electron microscopy of synaptic contacts on dendrite spines of the cerebral cortex", Nature, vol. 183, pp. 1592-1593. https://doi.org/10.1038/1831592a0

[2] Nimchinsky, E. A., Sabatini, B. L., and Svoboda, K. (2002): "Structure and function of dendritic spines", Annu. Rev. Physiol., vol. 64, pp. 313-353. https://doi.org/ 10.1146/annurev.physiol.64.081501.160008

[3] Hotulainen, P., and Hoogenraad, C. C. (2010): "Actin in dendritic spines: connecting dynamics to function", J. Cell Biol., vol. 189, pp. 619-629. https://doi.org/10.1083/jcb.201003008

[4] Sheng, M., and Kim, E. (2011): "The postsynaptic organization of synapses", Cold Spring Harb. Perspect. Biol., vol. 3: a005678. https://doi.org/10.1101/cshperspect.a005678

[5] Colgan, L. A., and Yasuda, R. (2014): "Plasticity of dendritic spines: subcompartmentalization of signaling", Annu. Rev. Physiol., vol. 76, pp. 365-385. https://doi.org/10.1146/annurev-physiol-021113-170400

[6] Levy, A. D., Omar, M. H., and Koleske, A. J. (2014): "Extracellular matrix control of dendritic spine and synapse structure and plasticity in adulthood", Front. Neuroanat., 8(116). https://doi.org/10.3389/fnana.2014.00116

[7] Trachtenberg, J. T., Chen, B. E., Knott, G. W., Feng, G., Sanes, J. R., Welker, E., et al. (2002): "Long-term in vivo imaging of experience-dependent synaptic plasticity in adult cortex", Nature, vol. 420, pp. 788-794. https://doi.org/10.1038/nature01273

[8] Zuo, Y., Yang, G., Kwon, E., and Gan, W. B. (2005b): "Long-term sensory deprivation prevents dendritic spine loss in primary somatosensory cortex", Nature, vol. 436, pp. 261265. https://doi.org/10.1038/nature03715

[9] Holtmaat, A., Wilbrecht, L., Knott, G. W., Welker, E., and Svoboda, K. (2006): "Experience-dependent and cell-type-specific spine growth in the neocortex", Nature, vol. 441, pp. 979-983. https://doi.org/10.1038/nature04783

[10] Hofer, S. B., Mrsic-Flogel, T. D., Bonhoeffer, T., and Hübener, M. (2009): "Experience leaves a lasting structural trace in cortical circuits", Nature, vol. 457, 313-317. https://doi.org/10.1038/nature07487

[11] Xu, T., Yu, X., Perlik, A. J., Tobin, W. F., Zweig, J. A., Tennant, K., et al. (2009): "Rapid formation and selective stabilization of synapses for enduring motor memories", Nature, vol. 462, pp. 915-919. https://doi.org/10.1038/nature08389

[12] Yang, G., Pan, F., and Gan, W. B. (2009): "Stably maintained dendritic spines are associated with lifelong memories", Nature, vol. 462, pp. 920-924. https://doi.org/10.1038/nature08577

[13] Tropea, D., Majewska, A. K., Garcia, R., and Sur, M. (2010): "Structural dynamics of synapses in vivo correlate with functional changes during experience-dependent plasticity in visual cortex", J. Neurosci., vol. 30, pp. 11086-11095. https://doi.org/10.1523/ JNEUROSCI.1661-10.2010 
[14] Attardo, A., Fitzgerald, J. E., and Schnitzer, M. J. (2015): "Impermanence of dendritic spines in live adult CA1 hippocampus”, Nature, vol. 523, pp. 592-596. https://doi.org/10.1038/nature14467

[15] Tjia, M. Yu, X. Jammu, L. S. Lu, J. and Zuo, Y. (2017): "Pyramidal Neurons in Different Cortical Layers Exhibit Distinct Dynamics and Plasticity of Apical Dendritic Spines", Front. Neural Circuits, 11(43), pp. 1-10, https://doi.org/org/10.3389/fncir.2017.00043

[16] Fu, M., and Zuo, Y. (2011). Experience-dependent structural plasticity in the cortex. Trends Neurosci. 34, 177-187. https://doi.org/10.1016/i.tins.2011.02.001

[17] Medini, P.(2014): "Experience-dependent plasticity of visual cortical microcircuits",Neuroscience,vol.278,pp.367-384 https://doi.org/10.1016/j.neuroscience.2014.08.022

[18] Yon, M. Mauger, S. \& Pickavance, L. (2013): "Relationships between dietary macronutrients and adult neurogenesis in the regulation of energy metabolism", British Journal of Nutrition, 109(9), 1573-1589. https://doi.org/10.1017/S0007 $11451200579 \mathrm{X}$.

[19] Witte, A. V. Kerti, L. Hermannstädter, H. M. Fiebach, J. B. Schreiber, S. J. Schuchardt, J. P. Hahn, A. and Flöel, A. (2014): "Long-Chain Omega-3 Fatty Acids improve brain function and structure in older adults", Cerebral Cortex, vol. 24, pp. 3059-3068, https://doi.org/10.1093/cercor/bht163

[20] Snyder, S. H. (2017): "A life of Neurotransmitters", Annu. Rev. Pharmacol. Toxicol. Vol. 57, pp. 1-11. https://doi.org/10.1146/annurev-pharmtox-010716-104511

[21] Stangl D, Thuret S. (2009): "Impact of diet on adult hippocampal neurogenesis", Genes Nutr 4: 271-282. https://doi.org/10.1007/s12263-009-0134-5

[22] Mundkur, N. (2005): "Neuroplasticity in children", Indian J Pediatr, 72(10), 855857.https://doi.org/10.1007/BF02731115

[23] Fabel K, Wolf SA, Ehninger D, Babu H, Leal-Galicia P, Kempermann G. (2009): "Additive effects of physical exercise and environmental enrichment on adult hippocampal neurogenesis in mice", Front Neurosci 3: 50. https://doi.org/10.3389/neuro. 22.002.2009

[24] Kobilo T, Liu QR, Gandhi K, Mughal M, Shaham Y, van Praag H. (2011): "Running is the neurogenic and neurotrophic stimulus in environmental enrichment", Learn Mem 18: 605609. https://doi.org/10.1101/1m.2283011

[25] Yancey SL, Overton JM. (1993): "Cardiovascular responses to voluntary and treadmill exercise in rats, J Appl Physiol 75: 1334-1340. https://doi.org/10.1152/jappl.1993. 75.3.1334

[26] Sharma HS, Cervos-Navarro J, Dey PK. (1991): "Increased blood-brain barrier permeability following acute short-term swimming exercise in conscious normotensive young rats" Neurosci Res 10: 211-221. https://doi.org/10.1016/0168-0102(91)90058$\underline{7}$

[27] Vissing J, Andersen M, Diemer NH. (1996): "Exercise-induced changes in local cerebral glucose utilization in the rat', J Cereb Blood Flow Metab 16: 729-736. https://doi.org/10.1097/00004647-199607000-00025

[28] Jin K, Zhu Y, Sun Y, Mao XO, Xie L, Greenberg DA. (2002): "Vascular endothelial growth factor (VEGF) stimulates neurogenesis in vitro and in vivo", Proc Natl Acad Sci USA 99: 11946-11950. https://doi.org/10.1073/pnas.182296499

[29] Sairanen M, Lucas G, Ernfors P, Castren M, Castren E. (2005): "Brain-derived neurotrophic factor and antidepressant drugs have different but coordinated effects on 
neuronal turnover, proliferation, and survival in the adult dentate gyrus", J Neurosci 25 : 1089-1094. https://doi.org/10.1523/JNEUROSCI.3741-04.2005

[30] Lane, S. J. and Schaaf R. C. (2010): "Examining the Neuroscience Evidence for SensoryDriven Neuroplasticity: Implications for Sensory-Based Occupational Therapy for Children and Adolescents", American Journal of Occupational Therapy, vol. 64, pp. 375390. https://doi.org/10.5014/ajot.2010.09069.

[31] Ibrayeva, A. and Bonaguidi, M. A. (2015): "Pushing and pulling on adult neural stem cells", Cell Stem Cell, vol. 16, pp. 451-452. https://doi.org/10.1016/ j.stem.2015.04.011

[32] Almone, J. B., Li, Y., Lee, S. W. Clemenson, G. D., Deng, W. and Gage, F. H. (2014): "Regulation and Function of Adult Neurogenesis: From Genes to Cognition", Physiol. Rev. 94(4), pp. 991-1026. https://doi.org/10.1152/physrev.00004.2014

[33] Zhao, C. Deng, W. and Gage, F. H. (2008): "Mechanisms and functional Implications of adult neurogenesis", Cell, vol. 132, pp. 645-660. https://doi.org/10.1016/j.cell.2008. $\underline{01.033}$

[34] Purves, D. (1988): "Body and brain, a trophic theory of neural connections", Cambridge, MA: Harvard University Press.

[35] Gottlieb, G. (1992): "Individual development and evolution. The genesis of novel behavior", New York: Oxford University Press.

[36] Gottlieb, G., Wahlsten, D., \&Lickliter, R. (1997): "The significance of biology for human development: A developmental psychobiological systems view”. In R. Lerner (Ed.), Handbook of child psychology: Vol. 1, Theoretical models of human development (5th ed.). New York: Wiley.

[37] Quartz, S. R., \& Sejnowski, T. J. (1997): “The neural basis of cognitive development: A constructivist manifesto", Behavioral and Brain Sciences, vol. 20, pp. 537-596. https://doi.org/10.1017/S0140525X97001581

[38] Stiles, J. (2000): "Neural plasticity and cognitive development", Developmental Neuropsychology, 18(2), pp. 237-272. https://doi.org/10.1207/S15326942DN1802_5

[39] Lemaire V, Tronel S, Montaron MF, Fabre A, Dugast E, Abrous DN. (2012): "Longlasting plasticity of hippocampal adult-born neurons", J Neurosci 32: 3101-3108. https://doi.org/10.1523/JNEUROSCI.4731-11.2012

[40] Tronel S, Fabre A, Charrier V, Oliet SH, Gage FH, Abrous DN. (2010): "Spatial learning sculpts the dendritic arbor of adult-born hippocampal neurons", Proc Natl Acad Sci USA, vol. 107, pp. 7963-7968. https://doi.org/10.1073/pnas.0914613107

[41] Kee N, Teixeira CM, Wang AH, Frankland PW. (2007): "Preferential incorporation of adult-generated granule cells into spatial memory networks in the dentate gyrus", Nat Neurosci., vol. 10, pp. 355-362. https://doi.org/10.1038/nn1847

[42] Stone SS, Teixeira CM, Zaslavsky K, Wheeler AL, Martinez-Canabal A, Wang AH, Sakaguchi M, Lozano AM, Frankland PW. (2011): "Functional convergence of developmentally and adult-generated granule cells in dentate gyrus circuits supporting hippocampus-dependent memory", Hippocampus, vol. 21, pp. 1348-1362. https://doi.org/10.1002/hipo.20845

[43] Tashiro A, Makino H, Gage FH. (2007): "Experience-specific functional modification of the dentate gyrus through adult neurogenesis: a critical period during an immature stage", J Neurosci., vol. 27, pp. 3252-3259. https://doi.org/10.1523/JNEUROSCI.4941$\underline{06.2007}$ 
[44] Pascual-Leone A, Amedi A, Fregni F, et al (2005): "The plastic human brain cortex", Annu. Rev. Neurosci., vol. 28, pp.377-401. https://doi.org/10.1146/annurev. neuro.27.070203.144216

[45] Warraich Z, Kleim JA (2010): "Neural plasticity: the biological substrate for

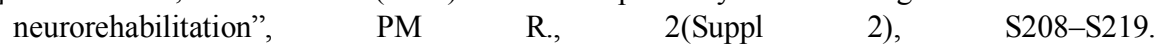
https://doi.org/10.1016/j.pmrj.2010.10.016

[46] May A (2011): "Experience-dependent structural plasticity in the adult human brain", Trends Cogn Sci., vol. 15, pp.475-482. https://doi.org/10.1016/j.tics.2011.08.002

[47] Kraus N, Chandrasekaran B (2010): "Music training for the development of auditory skills", Nat Rev Neurosci., vol. 11, pp. 599-605. https://doi.org/10.1038/nrn2882

[48] Yau SY, Lau BW, So KF (2011): "Adult hippocampal neurogenesis: a possible way how physical exercise counteracts stress", Cell Transplant, vol. 20, pp. 99-111. https://doi.org/10.3727/096368910X532846

[49] Cramer SC, Sur M, Dobkin BH, et al (2011): "Harnessing neuroplasticity for clinical applications", Brain, vol. 134, pp.1591-1609. https://doi.org/10.1093/brain/awr039

[50] Ernst C, Olson AK, Pinel JP, et al (2006): “Antidepressant effects of exercise: evidence for an adult-neurogenesis hypothesis?” J Psychiatry Neurosci., vol. 31, pp. 84-92.

[51] Greenwood BN, Fleshner M (2011): "Exercise, stress resistance, and central serotonergic systems", Exerc Sport Sci Rev., vol. 39, pp. 140-149. https://doi.org/10.1097/JES. 0b013e31821f7e45

[52] Knöchel C, Oertel-Knöchel V, O'Dwyer L, et al (2012): “Cognitive and behavioural effects of physical exercise in psychiatric patients", Prog Neurobiol., vol. 96, pp. 46-68. https://doi.org/10.1016/i.pneurobio.2011.11.007

[53] Fontan-Lozano, A. et al. (2008): "Molecular bases of caloric restriction regulation of neuronal synaptic plasticity”, Mol. Neurobiol., 38 (2), 167-177. https://doi.org/10.1007/ $\underline{\text { s12035-008-8040-1 }}$

[54] Mattson, M. P. Gleichmann, M. and Cheng, A. (2008): "Mitochondria in neuroplasticity and neurological disorders", Neuron, 60 (5), pp. 748 - 766. https://doi.org/10.1016/ j.neuron.2008.10.010

[55] Chan, D. C. (2006): "Mitochondria: dynamic organelles in disease, aging, and development", Cell, 125 (7), pp. 1241-1252. https://doi.org/10.1016/j.cell.2006. $\underline{06.010}$

[56] Hoppins, S. Lackner, L. Nunnari, J. (2007): "The machines that divide and fuse mitochondria”, Annu. Rev. Biochem., vol. 76, pp. 751-780. https://doi.org/10.1146/annurev.biochem.76.071905.090048

[57] Knott, A. B. et al., (2008), "Mitochondrial fragmentation in neurodegeneration", Nat. Rev. Neurosci., 9 (7), pp. 505-518. https://doi.org/10.1038/nrn2417

[58] Stranahan, A. M. et al., (2008): "Diet-induced insulin resistance impairs hippocampal synaptic plasticity and cognition in middle-aged rats", Hippocampus, 18 (11), pp. 10851088. https://doi.org/10.1002/hipo.20470

[59] Marques-Aleixo, I. et al., (2012): "Physical exercise as a possible strategy for brain protection: evidence from mitochondrial-mediated mechanisms", Prog. Neurobiol., 99 (2), pp. 149-162. https://doi.org/10.1016/j.pneurobio.2012.08.002

[60] Wrann, C. D. et al., (2013): "Exercise induces hippocampal BDNF through a PGC1alpha/FNDC5 pathway", Cell Metab., 18 (5), pp. 649-659. https://doi.org/10.1016/ j.cmet.2013.09.008 
[61] Moon, H. Y. et al., (2016): "Running-induced systemic cathepsin B secretion is associated with memory function”, Cell Metab., 24 (2), pp. 332 -340. https://doi.org/10.1016/ j.cmet.2016.05.025

[62] Raefsky, S. M., \& Mattson, M. P., (2017): “Adaptive responses of neuronal mitochondria to bioenergetic challenges: Roles in neuroplasticity and disease resistance", Free Radical Biology and Medicine, vol. 102, pp. 203-216. DOI: 10.1016/j.freeradbiomed.2016.11.045 https://doi.org/10.1016/j.freeradbiomed.2016.11.045

[63] Rohrer, T. (2006): "Image schemata and the brain". In B. Hampe, \& J. Grady (Eds.), From perception to meaning: Image schemas in cognitive linguistics. Berlin: Mouton de Gruyter.

[64] Edelman, G., \& Tononi, G. (2000a): “A universe of consciousness: How matter becomes imagination", Cambridge: Perseus Books.

[65] Edelman, G., \& Tononi, G. (2000b): “A universe of consciousness: How matter becomes imagination", New York: Basic Books.

[66] Kaag, J. (2008): "The neurological dynamics of the imagination", Phenom Cogn Sci. https://doi.org/10.1007/s11097-008-9106-2.

[67] Dornyei, Z. (2014): "Future self-guides and vision". In "The Impact of self-concept on language learning", Csizer, K. and Magid, M. (eds), Multilingual Matters/Channel View Publications. https://doi.org/10.21832/9781783092383-003

[68] Tan, A. - G. (2017): "Creative Imagination in Memorization in Mathematics Learning", Creative Contradictions in Education, vol. 1, pp. 249-264. https://doi.org/10.1007/9783-319-21924-0 14

[69] O' Craven, K. M. and Kanwisher, N. (2000): "Mental Imagery of Faces and Places Activates Corresponding Stimulus-Specific Brain Regions", Journal of Cognitive Neuroscience, 12(6), pp. 1013-1023 https://doi.org/10.1162/08989290051137549

[70] Hickok, G. (2009): "Eight Problems for the Mirror Neuron Theory of Action Understanding in Monkeys and Humans", Journal of Cognitive Neuroscience, 21(7), pp. 1229-1243 https://doi.org/10.1162/jocn.2009.21189

[71] Tang YY, et al. (2010): "Short-term meditation induces white matter changes in the anterior cingulate", Proc Natl Acad Sci USA, 107(35), pp. 15649-15652. https://doi.org/10.1073/pnas.1011043107

[72] Tang YY, Lu Q, Fan M, Yang Y, Posner MI (2012): "Mechanisms of white matter changes induced by meditation", Proc Natl Acad Sci USA, 109(26), pp.10570-10574. https://doi.org/10.1073/pnas.1207817109

[73] Posner MI, Tang YY, Lynch G (2014): "Mechanisms of white matter change induced by meditation training", Front Psychol., vol. 5, pp. 1220. https://doi.org/10.3389/fpsyg. $\underline{2014.01220}$

[74] Weible AP, Piscopo DM, Rothbart MK, Posner MI and Niell CM. (2017): "Rhythmic brain stimulation reduces anxiety-related behavior in a mouse model based on meditation training", Proc Natl Acad Sci., 114(10), pp. 2532-2537. https://doi.org/10.1073/pnas. 1700756114.

[75] Kim, M. J. et al. (2011): “Anxiety dissociates dorsal and ventral medial prefrontal cortex functional connectivity with the amygdala at rest”, Cereb. Cortex., vol. 21, pp. 1667-1673. https://doi.org/10.1093/cercor/bhq237

[76] Kyeong, S. Kim, J. Kim, D. J. Kim, H. E. and Kim, J.-J. (2017): "Effects of gratitude meditation on neural network functional connectivity and brain-heart coupling", Scientific Reports, 7(5058), pp. 1-15, https://doi.org/10.1038/s41598-017-05520-9

[77] Gallos, L. K., Makse, H. A. \& Sigman, M. (2012): “A small world of weak ties provides optimal global integration of self-similar modules in functional brain networks", Proc. 
Natl. Acad. Sci. USA, vol. 109, pp. 2825-2830. https://doi.org/10.1073/ pnas. 1106612109

[78] Kabat-Zinn J (2003): "Mindfulness-based interventions in context: Past, present, and future", Clinical Psychology: Science and Practice, vol. 10, pp. 144-156. https://doi.org/10.1093/clipsy.bpg016

[79] Salzberg S (1995): "Loving-kindness: The revolutionary art of happiness", Boston: Shambhala, pp. 1-7.

[80] Holzel BK, Ott U, Gard T, Hempel H, Weygandt M, et al. (2008): "Investigation of mindfulness meditation practitioners with voxel-based morphometry", Soc Cogn Affect Neurosci, vol. 3: pp. 55-61. https://doi.org/10.1093/scan/nsm038

[81] Lee, T. M. C. Leung, M.-K. Hou, W.-K. Tang, J. C. Y. Yin, J. So, K.-F. Lee, C.-F. and Chan, C.C.H. (2012): "Distinct Neural Activity Associated with Focused-Attention Meditation and Loving-Kindness Meditation", LoS ONE, 7(8): e40054. https://doi.org/10.1371/journal.pone.0040054

[82] Kumari, V. Antonova, E. Wright, B. Hamid, A. Hernandez, E. M. Schmechtig, A. and Ettinger, U. (2017): "The mindful eye: Smooth pursuit and saccadic eye movements in meditators and non-meditators", Consciousness and Cognition, vol. 48, pp. 66-75. https://doi.org/10.1016/j.concog.2016.10.008

[83] Teper, R., \& Inzlicht, M. (2013): "Meditation, mindfulness and executive control: The importance of emotional acceptance and brain-based performance monitoring", Social, Cognitive, and Affective Neuroscience, vol. 8, pp. 85-92. https://doi.org/10.1093/ 'scan $/$ nss045

[84] Brewer, J. A., Worhunsky, P. D., Gray, J. R., Tang, Y.-Y., Weber, J., \& Kober, H. (2011): "Meditation experience is associated with differences in default mode network activity and connectivity", Proceedings of the National Academy of Sciences of the United States of America, 108(50), pp. 20254-20259. https://doi.org/10.1073/pnas.1112029108

[85] Farb, N. A., Segal, Z. V., Mayberg, H., Bean, J., McKeon, D., Fatima, Z., \& Anderson, A. K. (2007).: "Attending to the present: Mindfulness meditations reveals distinct neural modes of self-reference", Social, Cognitive, and Affective Neuroscience, 2(4), pp. 313322.https://doi.org/10.1093/scan/nsm030

[86] Mason, M. F., Norton, M. I., Van Horn, J. D., Wegner, D. M., Grafton, S. T., \& Macrae, C. N. (2007): "Wandering minds: The default network and stimulus-independent thought", Science, vol. 315, pp. 393-395.https://doi.org/10.1126/science.1131295

[87] Brabosz cz C, Cahn BR, Levy J, Fernandez M, Delorme A (2017): "Increased Gamma Brainwave Amplitude Compared to Control in Three Different Meditation Traditions", PLoS ONE 12(1): e0170647.https://doi.org/10.1371/journal.pone.0170647

[88] Taren, A. Gianaros, P. Greco, C. Lindsay, E. Fairgrieve, A. Brown, K. W. Rosen, R. Ferris, J. L. Julson, E. Marsland, A. L. Creswell, J. D. (2017): "Mindfulness Meditation Training and Executive Control Network Resting State Functional Connectivity: A Randomized Controlled Trial", Psychosomatic Medicine, 79(6), pp. 674-683. https://doi.org/10.1097/PSY.0000000000000466

[89] Moore, A., Gruber, T., Derose, J., and Malinowski, P. (2012):“Regular, brief mindfulness meditation practice improves electrophysiological markers of attentional control", Front. Hum. Neurosci., 6(18), https://doi.org/10.3389/fnhum.2012.00018

[90] Malinowski, P. (2013): "Neural mechanisms of attentional control in mindfulness meditation", Frontiers in Neuroscience, 7(8), 1-11, https://doi.org/10.3389/fnins. $\underline{2013.0000}$ 
[91] Pavlov, S. V. Korenyok, V. V. Reva, N. V. Tumyalis, A. V. Loktev K. V. \& Aftanas, L. I. (2015): "Effects of long-term meditation practice on attentional biases towards emotional faces: An eye-tracking study", Cognition and Emotion, 29(5), http://dx.doi.org/10.1080/ $\underline{02699931.2014 .945903}$

[92] Sharma, V. Dharmendra Kumar, S. Ravi, P. (2017):"Computational Analysis of Brainwaves for Mind Relaxation during Meditation-A Survey", Asian Journal of Convergence in Technology, 3(3), http://www.asianssr.org/index.php/ajct/ article/view/2833>

[93] Abdulkader, S. N., Atia A. and Mostafa M.-S. M. (2015): "Brain computer interfacing: Applications and challenges", Egyptian Informatics Journal, vol. 16, pp. 213-230, https://doi.org/10.1016/j.eij.2015.06.002

[94] Vivar C. and Van Praag, H. (2013) "Functional circuits of new neurons in the dentate gyrus", Front. Neural Circuits, 7(15), pp. 1-13. https://doi.org/10.3389/fncir.2013. $\underline{00015}$

[95] Vadodaria, K. C., and Jess Berger, S. (2014): "Functional neurogenesis in the adult hippocampus: then and now", Front. Neurosci., 8(55). https://doi.org/10.3389/fnins. $\underline{2014.00055}$

\section{Authors}

A. Drigas is a Research Director at N.C.S.R. 'Demokritos', Institute of Informatics and Telecommunications, Net Media Lab, Agia Paraskevi, 153 10, Athens, Greece

M. Karyotaki is a Phd candidate in cognitive science and ICTs with N.C.S.R. 'Demokritos', Institute of Informatics and Telecommunications, Net Media Lab, Agia Paraskevi, 153 10, Athens, Greece

C. Skianis is an Associate Professor in the Department of Information and Communication Systems Engineering at the University of the Aegean, Karlovassi, Greece

Article submitted 13 June 2018. Final acceptance 23 October 2018. Final version published as submitted by the authors. 